\title{
ESTUDO DO CASO DE PRECIPITAÇÃO INTENSA SOBRE FOZ DO IGUAÇU-PR EM SETEMBRO DE 2015
}

\author{
RIQUETTI, Nelva Bugoni - nelvariquetti@hotmail.com \\ Programa de Pós-Graduação em Recursos Hídricos - Universidade Federal de \\ Pelotas/ UFPel
}

DORNELES, Viviane Rodrigues - vivianerdorneles@gmail.com

Programa de Pós-Graduação em Recursos Hídricos - Universidade Federal de

Pelotas/ UFPel

NUNES, André Becker - andre.nunes@ufpel.edu.br

Programa de Pós-Graduação em Recursos Hídricos - Universidade Federal de

Pelotas/ UFPel

\begin{abstract}
RESUMO: A compreensão das forçantes que desencadeiam eventos de chuva intensa é de extrema necessidade para possibilitar medidas de gestão ambiental. Com objetivo de analisar as forçantes que influenciaram o evento das tempestades no dia 07 de setembro de 2015 na cidade de Foz do Iguaçu-PR, o estudo do fenômeno meteorológico foi realizado por meio de análise de campos meteorológicos usando dados de reanálise do MERRA-2 e imagens de satélite do GOES-13 no período compreendido entre os dias 05 e 08 de setembro de 2015. Identificou-se que os eventos das tempestades foram causados pela presença de um Sistema Convectivo de Mesoescala (SCM), manifestando-se sobre forçantes térmicas oriundas de baixos níveis, influenciadas pela Baixa do Noroeste Argentino e por forçantes dinâmicas provenientes de altos níveis.
\end{abstract}

PALAVRAS-CHAVES: Eventos de chuva intensa, Sistema Convectivo de Mesoescala, Baixa do Noroeste Argentino.

\section{CASE STUDY OF INTENSE PRECIPITATION ON FOZ DO IGUAÇU-PR IN SEPTEMBER 2015}

ABSTRACT: The understanding of the forcing that triggers events of intense rainfall is of extreme necessity to enable environmental management measures. With the objective of analyzing the forcing, that influenced the event of the storms on September 7, 2015 in the city of Foz do Iguaçu-PR. The study of meteorological phenomena was accomplished by means of meteorological field analysis using MERRA-2 reanalysis data and GOES-13 satellite images in the period from 05 to 08 September 2015. It was identified that the events of the storms were caused by the presence of a Mesoscale Convective System (MCS), manifesting itself on low-level thermal forcing, influenced by the Northwestern Argentinean Low and by dynamic forcing from high levels.

KEYWORDS: Events of intense rainfall, Mesoscale Convective System, Northwestern Argentinean Low.

ESTUDIO DEL CASO DE PRECIPITACIÓN INTENSA SOBRE FOZ DO IGUAÇU-PR EN SEPTIEMBRE DE 2015

ABSTRACT: La comprensión de los forzantes que desencadenan eventos de lluvia intensa es de extrema necesidad para posibilitar medidas de gestión ambiental. Con el objetivo analizar los forzantes que influenciaron el evento de las tormentas en el día 07 de septiembre en la ciudad de Foz do Iguaçu-PR. El estudio que involucró el sistema meteorológico fue realizado por medio de análisis de campos meteorológicos utilizando datos de reanálisis de MERRA-2 e imágenes de satélite de GOES-13 en el período comprendido entre los días 05 a 08 de septiembre de 2015. Se identificó que los eventos de tormentas fueron provocados por la presencia de un Sistema Convectivo de Mesoescala (SCM), manifestándose sobre forzantes térmicas oriundas de bajos niveles, 
influenciados por la Baja del Noroeste Argentino y por forzantes dinámicas provenientes de altos niveles.

PALABRAS ClAVE: Eventos de lluvia intensa, Sistema Convectivo de Mesoescala, Baja del Noroeste Argentino.

\section{ÉTUDE DU CAS DE PRÉCIPITATIONS INTENSE SUR FOZ DO IGUAÇU-PR EN SEPTEMBRE 2015}

RÉSUMÉ: La compréhension du forçage qui déclenche des événements de pluies intenses est d'une extrême nécessité pour rendre possibles des mesures de gestion environnementale. Avec l'objectif d'analyser les forteresses qui ont influencé l'événement des tempêtes dans la journée du 7 septembre dans la ville de Foz do Iguaçu-PR. L'étude portant sur le système météorologique a été réalisée au moyen d'une analyse du champ météorologique à l'aide des données de réanalyse MERRA-2 et des images satellite GOES-13 pour la période du 05 au 08 septembre 2015. Il a été identifié les événements de tempêtes ont été provoqués par la présence d'un système convectif MesoScale (SCM), se manifestant sur le forçage thermique provenant des niveaux bas, influencés par le bas-nord-ouest de l'Argentine et par un forçage dynamique à des niveaux élevés.

MOTS-CLÈS: Évènements de fortes pluies, Système Convectif Méso-échelle, Nord-Ouest Argentin Inférieur.

\section{INTRODUÇÃO}

Em termos meteorológicos ou climatológicos, períodos com secas prolongadas ou inundações, bem como a ocorrência de temperaturas muito baixas ou muito altas, são chamados de eventos extremos, devido ao fato de apresentarem magnitudes que ultrapassam a capacidade de resiliência do ecossistema, gerando impactos ambientais destrutivos, como enchentes, furacões, ressacas, secas e deslizamentos de terra (MARENGO, 2010).

Diversos trabalhos, abordando diferentes metodologias e objetivos, analisaram eventos de precipitação intensa em diferentes regiões do Brasil. Por exemplo, Wanderley et al. (2018) investigaram as frequências, as tendências e o tempo de recorrência dos eventos pluviométricos extremos na cidade do Recife-PE, resultando em trabalho essencial ao planejamento da cidade haja vista a suscetibilidade da mesma quanto às chuvas intensas. Sanches et al. (2015) identificaram a ocorrência de eventos intensos de precipitação na região do Alto Uruguai Gaúcho (RS) no período de 8 dias consecutivos, indicando o papel de frentes estacionárias e semiestacionárias com duração mínima de 36 horas na ocorrência de tais eventos. Reboita et al. (2017) descreveram as características atmosféricas para elevados totais de precipitação que foram precursores de dois episódios de inundação e alagamento na cidade de ItajubáMG, encontrando que muitos casos estiveram associados à atuação da Zona de Convergência do Atlântico Sul. Seluchi et al. (2016) mostraram que as frentes frias responsáveis pelos maiores volumes pluviométricos diários na região serrana do Rio de Janeiro-RJ ocorrem no semestre quente do ano. Steinke et al. (2006) apontaram que o encontro da umidade vinda da Amazônia com as frentes frias provenientes do Sudoeste acarretou na formação das áreas de instabilidade de outubro de 2006 no Distrito Federal. Nunes e Da Silva (2013) analisaram o aumento de frequência de eventos de chuva intensa na maior parte das cidades do leste de Santa Catarina, observando uma tendência linear positiva nas últimas décadas e um aumento heterogêneo dos eventos para um cenário futuro entre 2071 a 2100. Lima e Amorim (2014) observaram para a cidade de São Carlos-SP o que outros autores verificaram para outras localidades: a influência da urbanização nas consequências de um evento de 
precipitação intensa, refletindo o aumento das áreas urbanas na intensificação da concentração das chuvas. Lohmann e Santos (2015) identificaram padrões de alagamentos em Curitiba-PR, sendo um padrão associado a chuvas convectivas e outro padrão relacionado a dinâmica da entrada de frentes frias. Coutinho et al. (2017) observaram o papel do vórtice ciclônico do Nordeste Brasileiro em um evento extremo no Ceará, resultando em núcleos de convergência de umidade associados a chuvas intensas no estado. Nunes e Pereira (2017) indicaram, no geral, aumento na frequência dos casos com potencial para alagamentos em cidades do Rio Grande do Sul para um cenário futuro e Fonseca et al. (2017) apontam que em um cenário de aumento das emissões de gases de efeito estufa, ocorrerá uma redução de $1 / 3$ no total de chuvas no verão, embora aumente a frequência dos eventos extremos no final do século XXI.

O clima da região Sul do Brasil apresenta contraste nos regimes de precipitação e temperatura, em parte devido à localização geográfica e ao relevo da região. De acordo com Grimm (2009) a precipitação apresenta transição bem marcada de regime ao norte da região Sul do Brasil, com estação chuvosa no início da primavera e terminando no início do outono, resultando em grande diferença nos regimes de precipitação entre o verão e inverno, enquanto que ao sul ocorre um regime de chuvas bem distribuídas ao longo do ano. Já a temperatura apresenta maior amplitude na região sul, devido principalmente a maior variação de radiação solar recebida entre o inverno e o verão. Reboita et al. (2010) classifica os regimes de precipitação em oito regiões das quais a região 4 refere-se a região Sul do Brasil, Sul do Paraguai e Uruguai, onde a precipitação é praticamente homogênea ao longo do ano, com total anual elevado (1050-1750 mm/ano) sendo ainda maior no oeste do sul do Brasil na fronteira com o Paraguai (1750-2100 mm/ano). Nesta sequência de ideias, a cidade de Foz do Iguaçu-PR, segundo a classificação climática estabelecida por Koppen (1931), é classificada como clima Subtropical de Altitude, sem estação seca, com temperatura média anual entre 210 e $220 C$, precipitação média anual entre 1600 e 1800 milímetros (mm), evapotranspiração anual média de 1100 a 1200 mm e umidade relativa anual entre 75 e 80\% (IAPAR, 2018).

Conforme Seluchi e Garreaud (2012) a Baixa do Chaco (BCH) é um sistema sinótico característico da estação chuvosa na América do Sul e afeta especialmente a baixa troposfera, sendo associada a anomalias de temperatura, vento atuante na porção tropical e subtropical do continente. A BCH se desenvolve em uma atmosfera mais instável do ponto de vista termodinâmico, porém menos afetada pela dinâmica das latitudes médias, inserindo-se em uma troposfera verticalmente mais estendida e apresenta uma estrutura mais barotrópica, típica de latitudes tropicais (SELUCHI e SAULO, 2012). Este sistema pode ser observado em campos de pressão ao nível médio do mar, localizandose aproximadamente entre $15-25^{\circ} \mathrm{S}$ e $60-65^{\circ} \mathrm{W}$, com seu centro entre $230 \mathrm{~S}$ e $600 W$. De acordo com Lichtenstein (1980), este sistema de baixa se localiza na região do Chaco Paraguaio-Boliviano entre Bolívia e Paraguai.

A BCH influencia o tempo no centro-norte da Argentina, sul da Bolívia, no Paraguai e nas Regiões Sul e Sudeste e em parte das Regiões Centro-Oeste e a interação com a Alta da Bolívia pode influenciar o tempo no Norte do Brasil. No verão, a BCH, se localiza entre o norte da Argentina, Paraguai, Mato Grosso do Sul e o sul da Bolívia. Já no inverno a $\mathrm{BCH}$ não aparece, confirmando seu caráter térmico, gerada principalmente pela liberação de calor latente, produto 
da convecção observada na área de atuação deste sistema, não devendo ser confundida com a Baixa do Noroeste Argentino (BNOA) que é um sistema influenciado pela orografia e dos sistemas transientes (ESCOBAR e SELUCHI, 2012). Essa diferença existente entre a BCH e BNOA possibilita a compreensão do desenvolvimento simultâneo da $\mathrm{BCH}$ e da Alta da Bolívia (LENTERS e COOK, 1999). A Alta da Bolívia é um sistema de alta pressão em altos níveis, associada com intenso aquecimento superficial, fluxos de calor sensível e latente (majoritariamente), e altas taxas de precipitação, localizada nas proximidades sobre a Bolívia (JONES e HOREL, 1990).

O regime de monção na região central da América do Sul começa durante a primavera com aumento da convecção sobre o noroeste da bacia Amazônica a meados de setembro, avançando para o Sudeste do Brasil até atingir a longitude de $480 \mathrm{~W}$ em novembro, havendo sequência de fase ativa e inativa estando as fases atmosféricas anômalas quase opostas entre si. Devido a essa distinção são utilizados, além do campo da precipitação, outras variáveis como por exemplo os campos da pressão e circulação do vento em baixos e altos níveis para caracterizar um período ativo e inativo do regime (GAN et al., 2009).

Segundo o jornal G1 (2015), no final da tarde do dia 07 de setembro de 2015 os danos ocasionados por uma tempestade afetaram pelo menos oito cidades no oeste do Paraná, assim como regiões no sudoeste do estado. Houve queda de granizo nos municípios de Marechal Cândido Rondon, Foz do Iguaçu, Céu Azul, Maripá, Missal, Guaíra, Matelândia e Santa Tereza do Oeste. Foram registrados estragos em imóveis, problemas estruturais em escolas e creches, destelhamento de casas, quedas de árvores e aulas suspensas durante a semana. A região sul da cidade de Foz do Iguaçu, onde está localizado o bairro Porto Meira, foi a mais afetada, com o destelhamento de $95 \%$ de suas residências, deixando centenas de desabrigados. O município declarou estado de emergência após estragos. A região fica próxima à fronteira com Puerto Iguazú, na Argentina, que também registrou estragos, assim como Presidente Franco, no Paraguai onde os danos foram semelhantes, conforme reportado pelo jornal Última Hora (2015), com aproximadamente 6.000 casas afetadas pelo fenômeno.

De acordo com o jornal Gazeta do Povo (2015), em uma hora choveu o equivalente a $20 \%$ da precipitação média histórica do mês de setembro, acumulada em 136,25 mm (ANA, 2018). Na região do Aeroporto de Foz do Iguaçu foram $23,2 \mathrm{~mm}$ de chuva concentrada, com rajadas de vento de 75 $\mathrm{km} / \mathrm{h}$ entre às 20 e 21 horas do horário local. Cidades próximas a Foz do Iguaçu, como em São Miguel do Iguaçu, foi registrado $27 \mathrm{~mm}$, em Capitão Leônidas Marques 30mm e Cascavel 56,2 mm entre os dias 7 e 8 de setembro de 2015 (CEMADEN, 2018).

Para o previsor do tempo, é fundamental o conhecimento do ambiente de grande escala associado a eventos intensos como este. Neste contexto, é apresentada a análise do ciclo de vida do Sistema Convectivo de Mesoescala (SCM) que ocorreu no dia 07 setembro de 2015 em Foz do Iguaçu, com a finalidade de determinar a configuração sinótica associada ao fenômeno.

\section{MATERIAL E MÉTODOS}


A análise do estudo do caso em questão é feita por meio de campos meteorológicos, obtidos de dados de reanálises do Modern Era RetrospectiveAnalysis for Research and Applications - Version 2 (MERRA-2) (GELARO et al., 2017). Os dados têm resolução espacial de $0.66^{\circ}$ de longitude e $0.5^{\circ}$ de latitude (cerca de $50 \mathrm{~km}$ na direção latitudinal), 42 níveis verticais e intervalo de tempo de 6 horas, para o período de quatro dias (05 a 08 de setembro de 2015), com domínio espacial cobrindo a América do Sul e oceanos adjacentes. São usados dados de pressão a nível médio do mar ( $\mathrm{pnmm})$, direção e magnitude do vento, altura geopotencial, temperatura do ar e umidade específica para diferentes níveis verticais. A análise em altos níveis é fundamental no entendimento do ciclo de vida de sistemas em superfície (BLUESTEIN, 1993; NUNES, 2017). A nebulosidade associada ao sistema é observada por meio de imagens do satélite GOES-13 (Geostationary Operational Environmental Satellite 13), obtidas da Divisão de Satélites e Sistemas Ambientais do Instituto Nacional de Pesquisas Espaciais (DSA/INPE). Também do DSA/INPE será observada a estimativa de precipitação por satélite e radar do Hidroestimador.

\section{RESULTADOS E DISCUSSÕES}

Campos sinóticos indicaram que no dia 07 de setembro de 2015 ocorreu a presença da Baixa do Noroeste Argentino (BNOA) sobre a América do Sul, conforme definição de Seluchi e Saulo (2012). A Figura 1 apresenta o campo de linha de corrente e magnitude do vento em $850 \mathrm{hPa}$ para dois dias antes e um dia depois do dia 07/09 (Figura 1C), para observar o desenvolvimento e dissipação do sistema. Também é possível observar que no campo de pnmm a região do evento a ser analisado (aproximadamente em $250 \mathrm{~S}$ e 540W), está sob a influência do centro de baixa caracterizada por valores relativamente baixos de pnmm, chegando a $1002 \mathrm{hPa}$. 


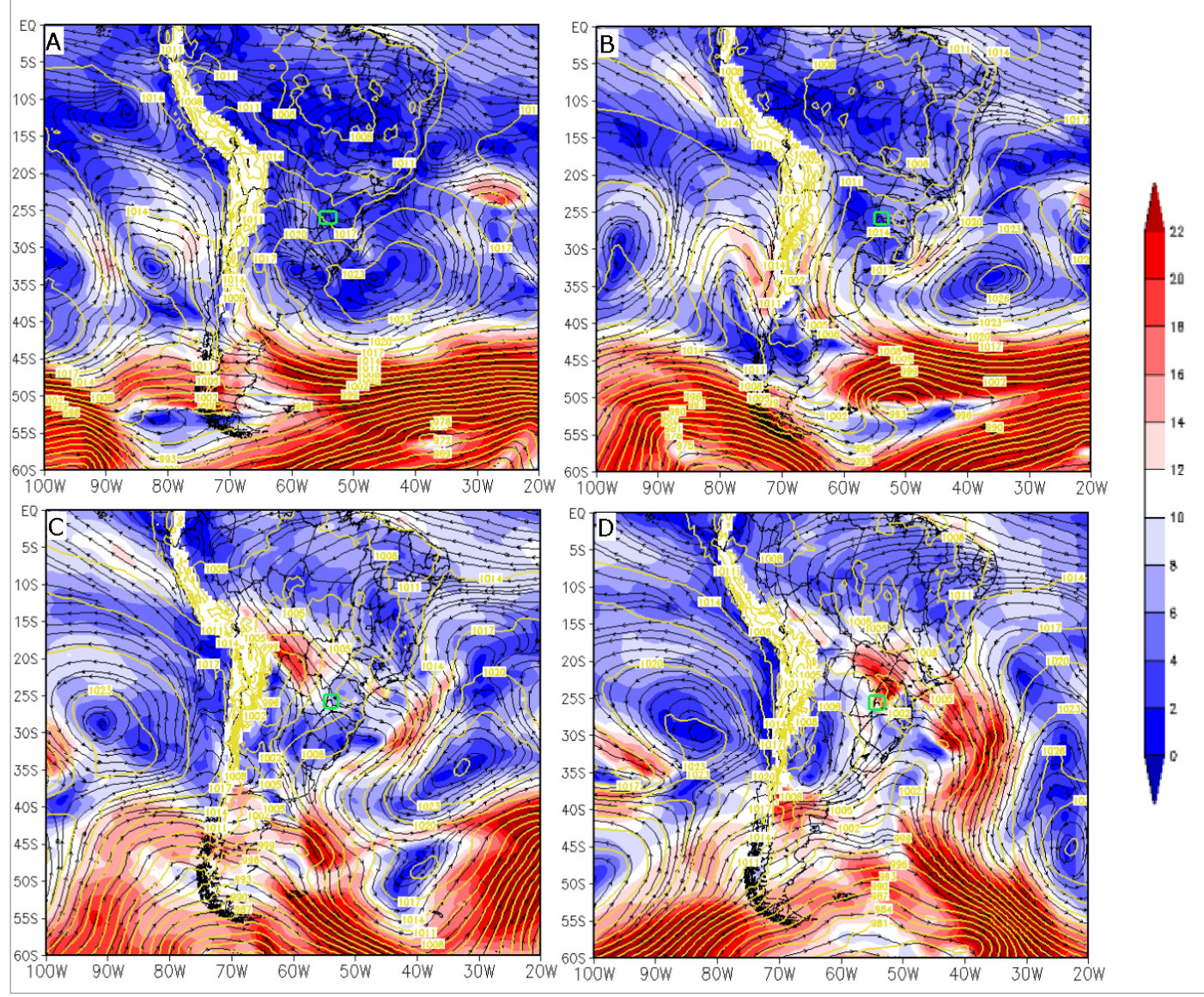

Figura 1 - Campo de pnmm em hPa (contornos em laranja), linha de corrente (contornos em preto) e magnitude do vento (sombreado) em m s-1 em $850 \mathrm{hPa}$. (A) 05/09 18UTC, (B) 06/09/18UTC, (C) 07/09 18UTC, (D) 08/09 18UTC, o polígono em verde indica a região afetada pelas tempestades.

Na Figura $1 \mathrm{~A}$ e $1 \mathrm{~B}$ pode-se observar o aumento progressivo da magnitude do vento de norte e a diminuição da pnmm indicando o desenvolvimento do sistema na região central da BNOA (pnmm a $1005 \mathrm{hPa}$ ). Na sequência, na Figura $1 \mathrm{C}$ se verifica a região afetada pelas tempestades, destacada em polígono verde para as 18:00 UTC do dia 07/09/2015, assim como a possível presença do Jato de Baixos Níveis (JBN), de acordo com Bonner (1968). Salio et al. (2007) explicam que o JBN Sul Americano tem um papel importante, transportando calor e umidade da bacia amazônica para o sul nas planícies centrais do Sudeste da América do Sul, gerando condições ambientais ideais para a iniciação da convecção e crescimento em SCMs. Fundamentado pelo exposto, podemos entender que a BNOA no dia 07/09 foi intensificada pelo JBN. Na dissipação do sistema (Figura 1D) é possível visualizar um desvio na direção do vento e aumento da magnitude do mesmo sobre a região Centro Oeste e Sul do Brasil.

Observa-se na Figura 2, o desenvolvimento e dissipação do sistema no decorrer do dia 07/09. A linha de corrente em $850 \mathrm{hPa}$ indica que o sentido do escoamento é de norte, trazendo calor e umidade da Amazônia. A advecção 
positiva de temperatura (transporte de massa tropical em baixos níveis) é uma forçante ciclogenética de acordo com a teoria quase-geostrófica, e está frequentemente associada a tempestades severas (MADDOX e DOSWELL, 1982). Na Figura 2, é possível analisar que no transcorrer do dia há um aumento da magnitude do vento de norte desde latitudes equatoriais, atingindo sua máxima intensificação ao leste dos Andes na região da BNOA (Figura 2C), assim como uma diminuição da pnmm denotando uma região favorável para convecção.

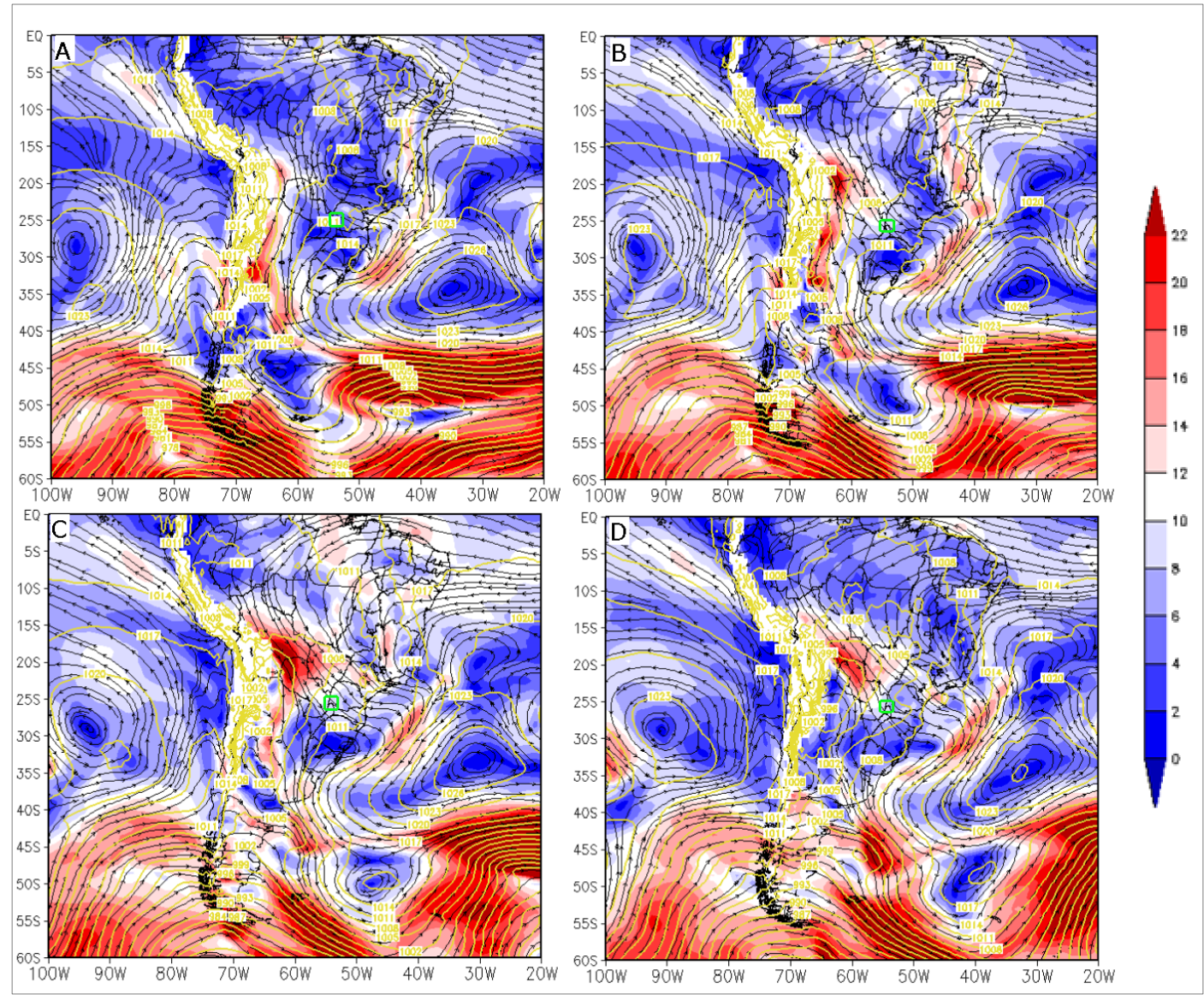

Figura 2 - Campo de pnmm em hPa (contornos em laranja), linha de corrente (contornos em preto) e magnitude do vento (sombreado) em m s-1 em $850 \mathrm{hPa}$. (A) 07/09 00UTC, (B) 07/09 06UTC, (C) 07/09 12UTC, (D) 07/09 18UTC, o polígono em verde indica a região afeta pelas tempestades.

Corroborando com o exposto acima, pode-se observar na Figura 3, sobre a região em estudo, que existe uma região predominante de advecção quente (onde o escoamento é de norte na Figura 2C). 


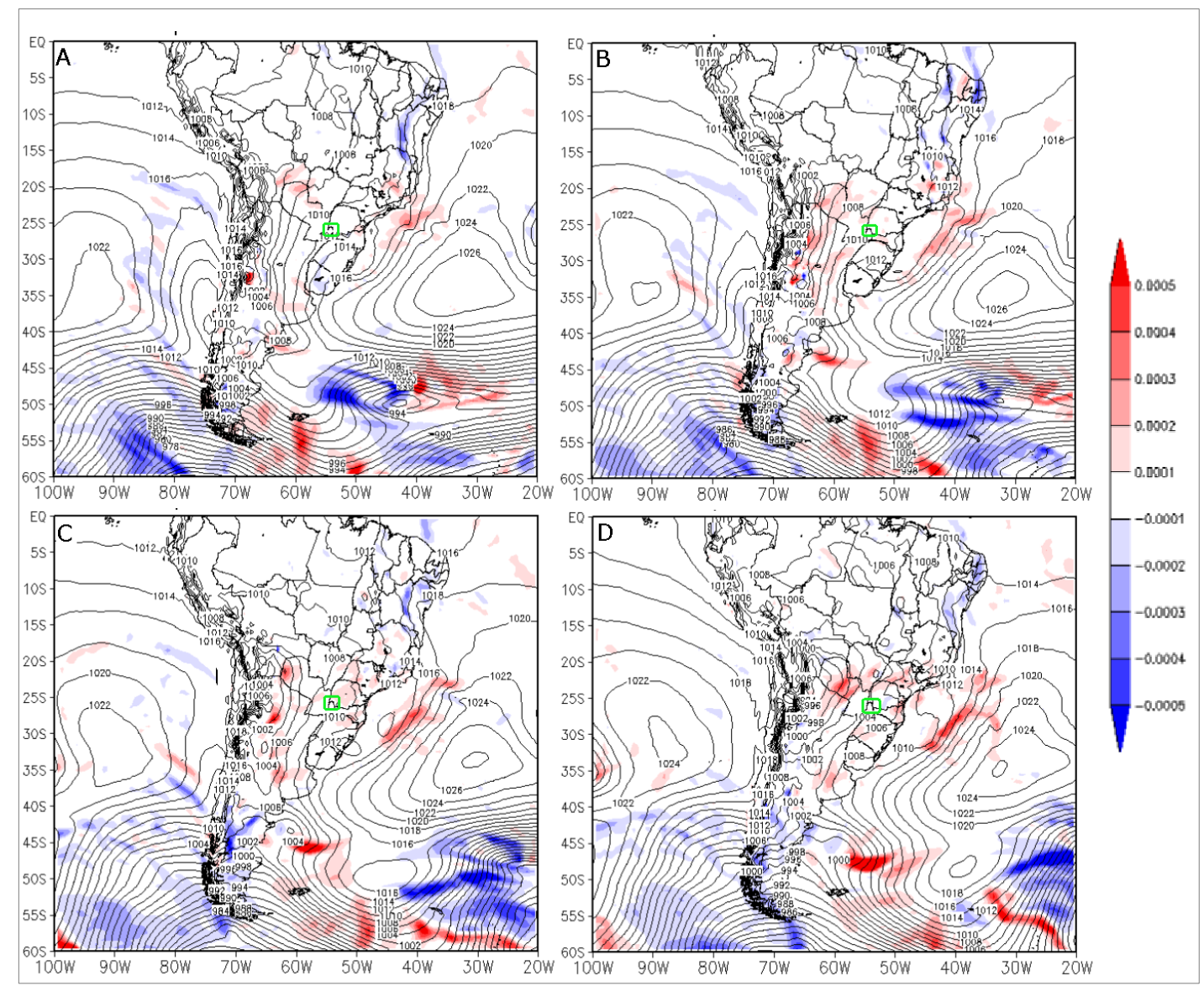

Figura 3 - Campo de pnmm em hPa (contornos em preto) e campos de advecção de temperatura em $850 \mathrm{hPa}$ (sombreado) em K s-1. (A) 07/09 00UTC, (B) 07/09 06UTC, (C) 07/09 12UTC, (D) 07/09 18UTC, o polígono em verde indica a região afetada pelas tempestades.

A Figura 4 mostra o campo de altura geopotencial em $500 \mathrm{hPa}$ ao longo dos dias. Observa-se no dia 07 (Figura 4C) um cavado em níveis médios, indicando que a região das tempestades estava sob a ação de AVC (advecção de vorticidade ciclônica), o que de acordo com a teoria quase-geostrófica indica movimento ascendente e queda da altura geopotencial em superfície (Figura 5) e, consequentemente, chance de instabilidade (HOLTON, 2004). No dia seguinte, o cavado em $500 \mathrm{hPa}$ segue sua trajetória esperada para leste, ficando sobre a região das tempestades o eixo do cavado, indicando uma atmosfera mais fria, associada ao anticiclone pós-frontal em superfície, que dissipa as tempestades.

$\mathrm{Na}$ Figura $5 \mathrm{~A}$ é possível observar que a leste do cavado em $500 \mathrm{hPa}$ nota-se predomínio de AVC, embora não exatamente sobre Foz do Iguaçu. A Figura 5B mostra a tendência (dia 07 - dia 06) de geopotencial em $1000 \mathrm{hPa}$, indicando queda devido a AVC e ao movimento ascendente. 

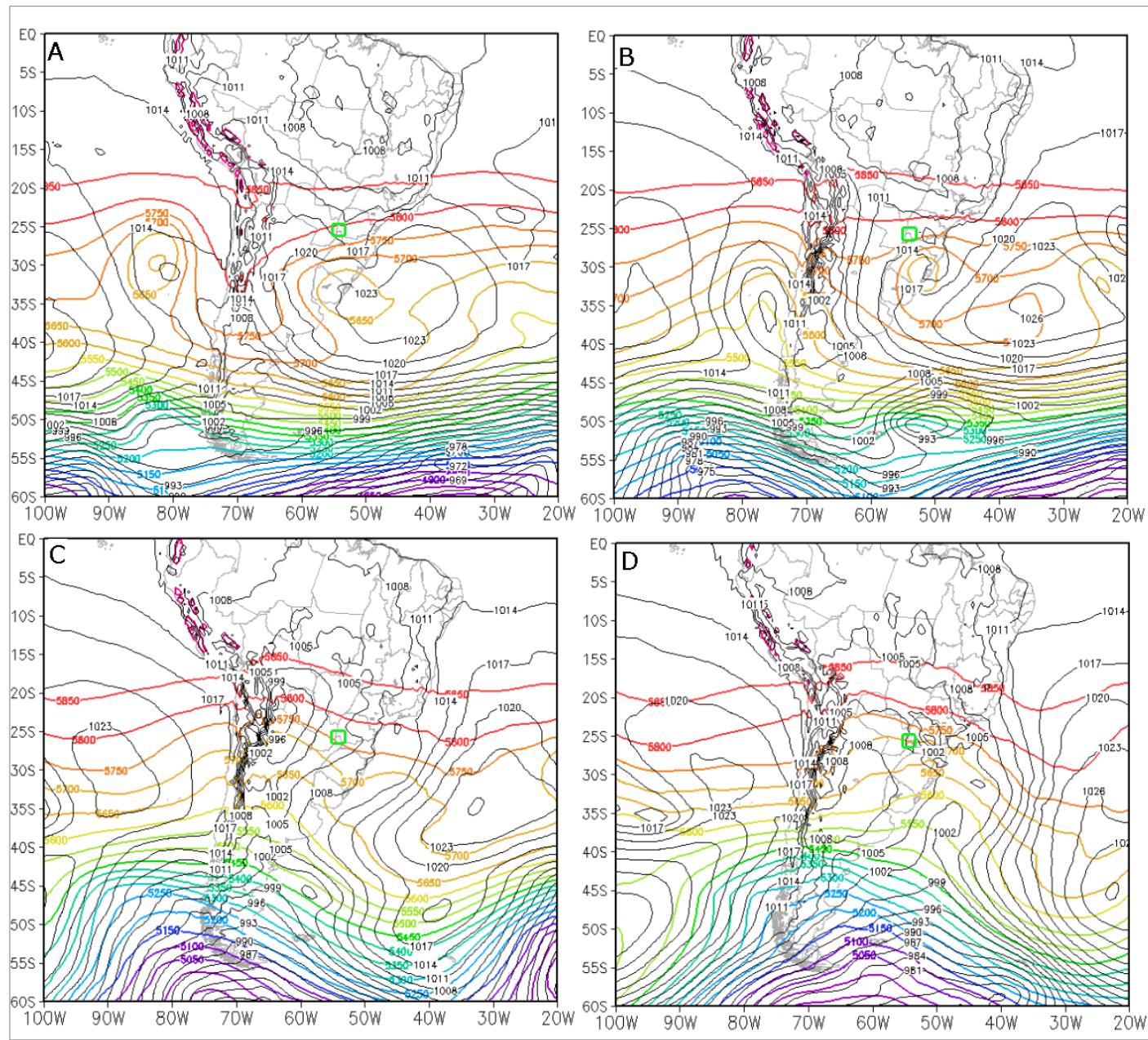

Figura 4 - Campo de pnmm em hPa (contorno preto) e altura geopotencial em $500 \mathrm{hPa}$ (contorno colorido) em mgp. (A) 05/09 18UTC, (B) 06/09 18UTC, (C) 07/09 18UTC, (D) 08/09 18UTC, o polígono em verde indica a região afetada pelas tempestades.
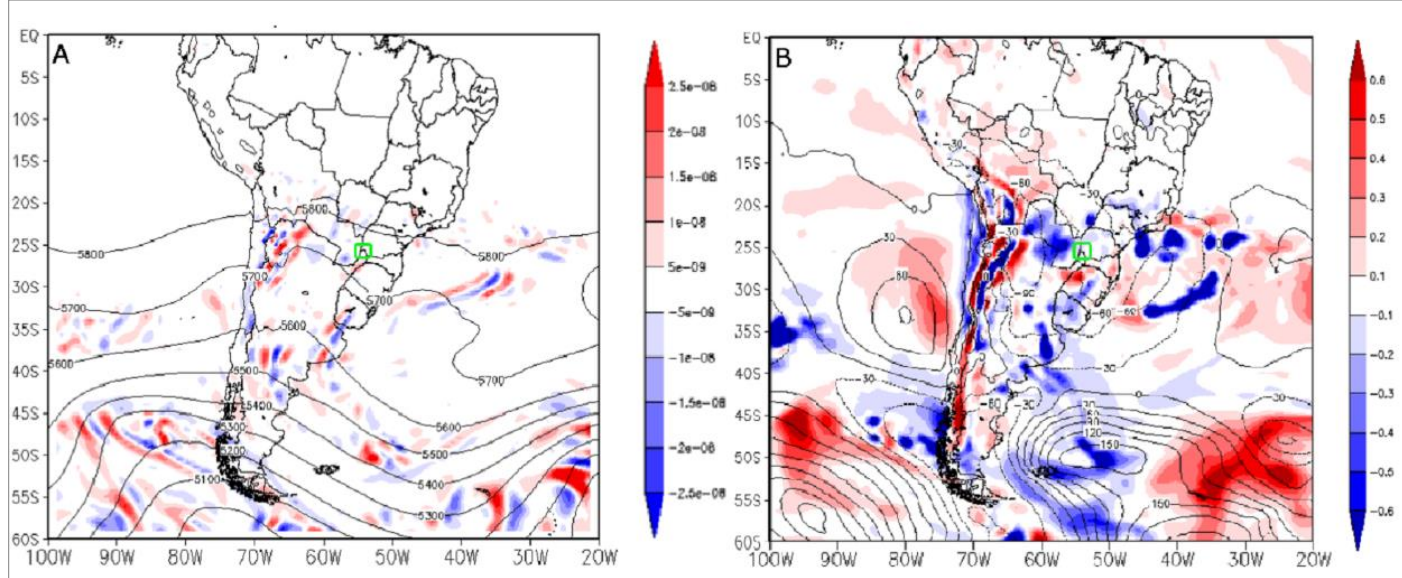

Figura 5 - (A) Campo de advecção de vorticidade em 500hPa (sombreado) em s-2 e campo de pressão a nível médio do mar (contorno em preto) em $\mathrm{hPa}$, (B) tendência de geopotencial em $1000 \mathrm{hPa}$ (contorno em preto) em hPa e ômega em $500 \mathrm{hPa}$ 
(sombreado) em Pa s-1 em 07/09 18UTC, o polígono em verde indica a região afetada pelas tempestades.

Seluchi e Saulo (2012) indicam que o campo térmico na média e baixa troposfera, onde a $\mathrm{BCH}$ e a BNOA se desenvolvem, pode ser avaliado por meio da espessura da camada entre 500 e 1000 hPa. Na Figura 6 pode-se observar possível instabilidade na região da BNOA localizada dentro de uma camada mais quente e verticalmente mais profunda, assim como a região das tempestades (250S e 540W). Na Figura 6D a região de camada mais fina se aproxima, indicando advecção fria (o que é esperado, haja vista as características baroclínicas da BNOA), observada pela figura 7, para este horário (18UTC do dia 08/09), que de acordo com a teoria quase-geostrófica está associada a movimentos subsidentes e, portanto, dissipação das tempestades.
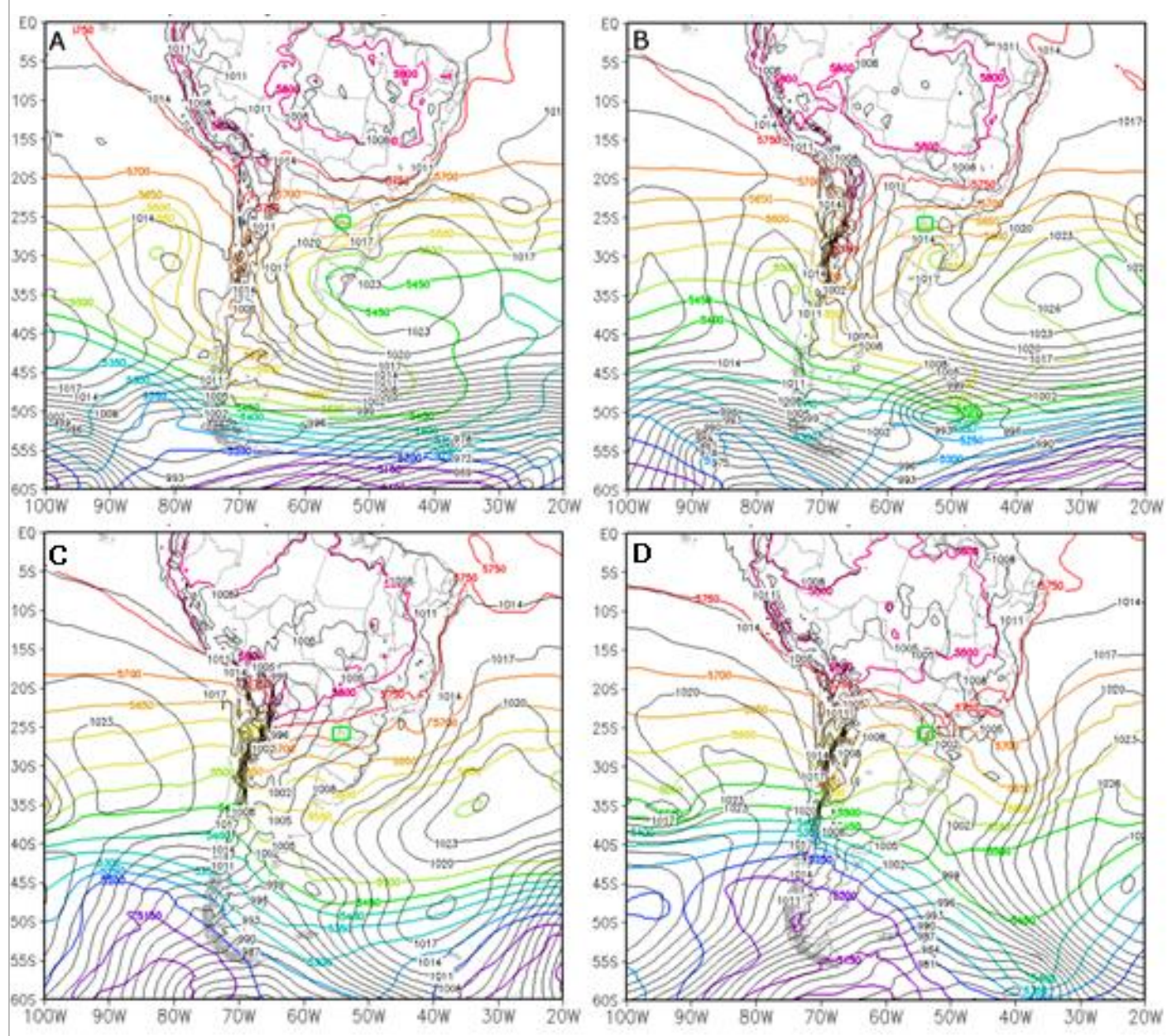

Figura 6 - Campo de pnmm (contorno preto) em hPa e espessura entre 500 e $1000 \mathrm{hPa}$ (contornos coloridos) em mgp. (A) 05/09 18UTC, (B) 06/09 18UTC, (C) 07/09 18UTC, (D) 08/09 18UTC, o polígono em verde indica a região afetada pelas tempestades. 


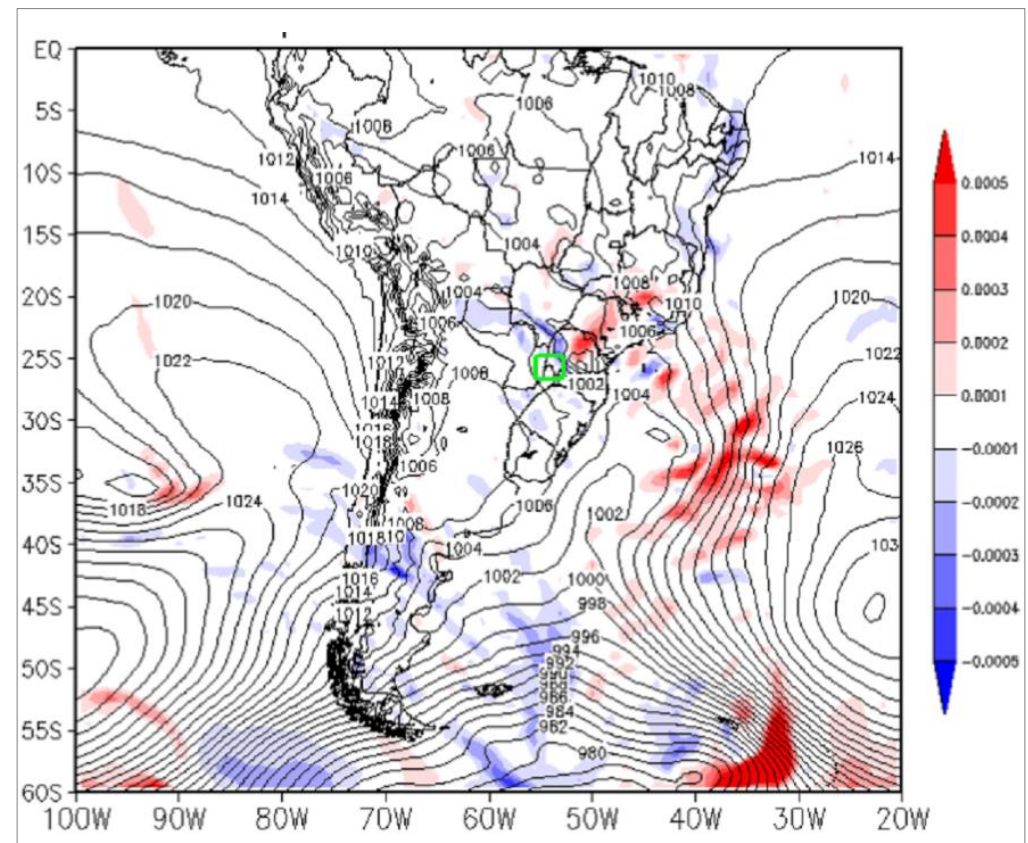

Figura 7 - Campo de pnmm em hPa (contorno preto) e advecção de temperatura em $850 \mathrm{hPa}$ (sombreado) em K s-1 para o dia 08/09 as 18 UTC, o polígono em verde indica a região afetada pelas tempestades.

Pode-se notar na Figura 8 a presença do jato subtropical em $250 \mathrm{hPa}$ sobre a região em estudo, favorecendo a intensificação de instabilidade nos sistemas de baixa pressão. Neste caso, tratando-se de sistema convectivo associado à BNOA, considera-se que a forçante termodinâmica possui um papel primário, seguido pela influência da dinâmica em altos níveis ao intensificar a instabilidade já estabelecida em baixos níveis. No dia das tempestades percebese a difluência do escoamento na Figura $8 \mathrm{C}$, aumentando a severidade da instabilidade em superfície (BLUESTEIN, 1993). Resultado encontrado por Amaral (2014), na análise dos complexos convectivos sobre a região sul da América do Sul entre 2005-2010, indica que as maiores taxas de precipitação média ocorreram relacionadas a presença do JBN e, em maiores extensões, com a presença da corrente de jato.

A Figura 9 mostra imagens de satélite do canal de temperatura realçada para o período, onde se percebe o deslocamento das tempestades a partir das 22:00 UTC do dia 07/09/2015, sendo possível observar os núcleos de maior convecção, com intervalo entre as imagens a cada 30 minutos. Na Figura 9A já é possível observar núcleos de convecção deslocando-se para a região de estudo, intensificando-se na hora seguinte, conforme Figuras 9B e C, e com maior intensificação e abrangência as 23:30 UTC (Figura 9D). Por ser um evento convectivo com duração aproximada de 3 horas, se observa que no período das 22:00 às 23:30 UTC foi o horário de máxima atuação das tempestades que geraram precipitação intensa no dia do evento. 

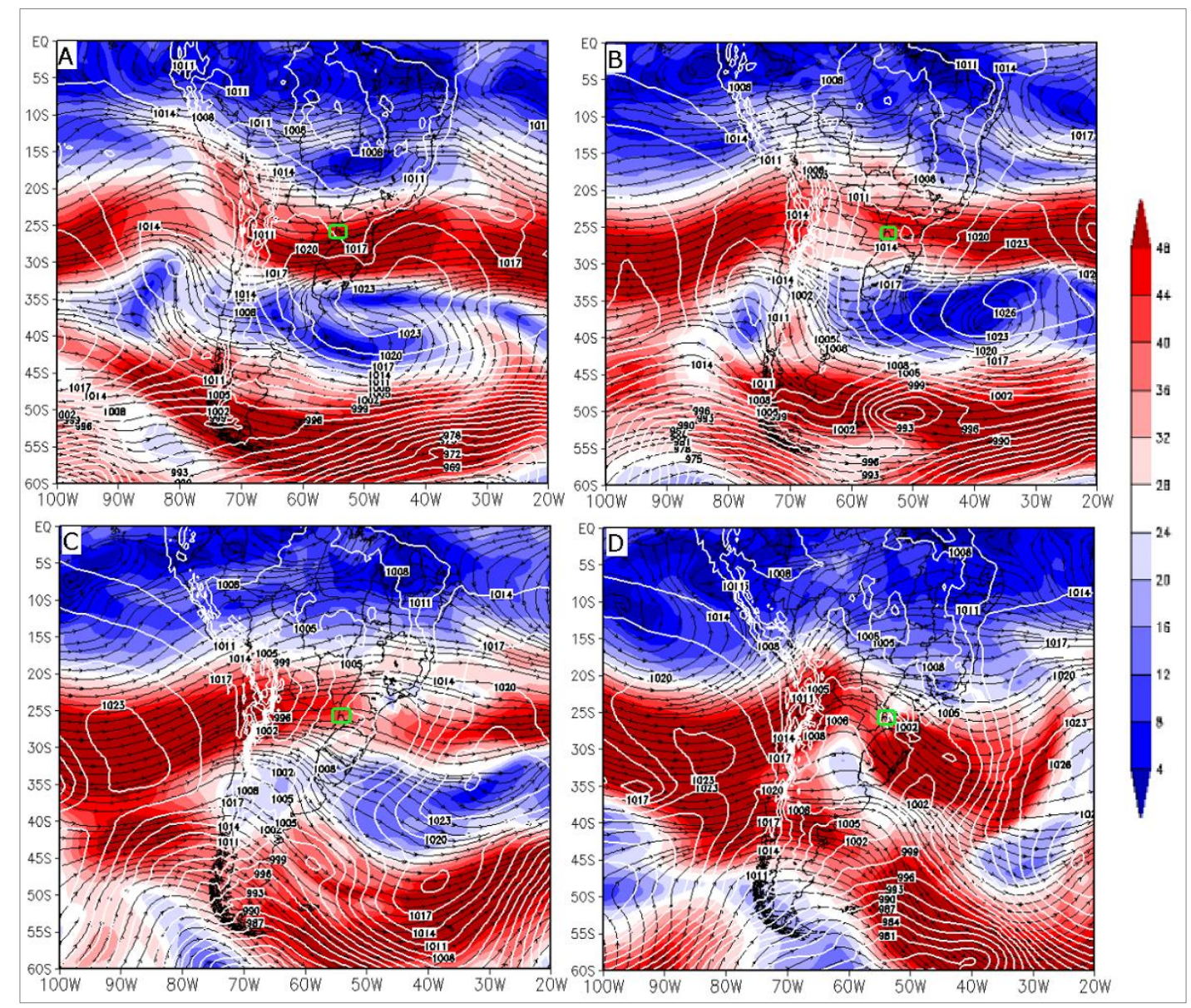

Figura 8 - Campo de pnmm em hPa (contorno branco), linha de corrente (linhas em preto) e magnitude do vento (sombreado) em ms-1 em $250 \mathrm{hPa}$. (A) 05/09 18UTC, (B) 06/09 18UTC, (C) 07/09 18UTC, (D) 08/09 18UTC, o polígono em verde indica a região afetada pelas tempestades.

Na Figura 10 é possível observar a precipitação acumulada das 12:00 UTC do dia 08/09/15 de acordo com o Hidroestimador (DSA/INPE, 2018). Em conformidade com as imagens de satélite e do Hidroestimador, registros de pluviômetros no dia 08/09 indicam para cidades próximas a Foz do Iguaçu precipitação significativa em Campo Mourão com 114,5 mm, Ivaí 76 mm, Castro $62,2 \mathrm{~mm}$, Maringá $37,5 \mathrm{~mm}$, Curitiba $26,8 \mathrm{~mm}$ e Londrina com 52,6 mm (INMET, 2018).

O campo de temperatura do ar em $850 \mathrm{hPa}$ mostra a presença de massa tropical que se desloca meridionalmente, a leste dos Andes, fortalecendo a BNOA, como pode se perceber até o dia 7 (Figura 11C), indicando a advecção quente sugerida pela Figura 3. Tal aumento da temperatura mostra-se coerente com caráter térmico da BNOA. Já no dia 8 (Figura 11D) nota-se declínio da temperatura associado a chegada de um sistema frontal e consequente dissipação do sistema. 

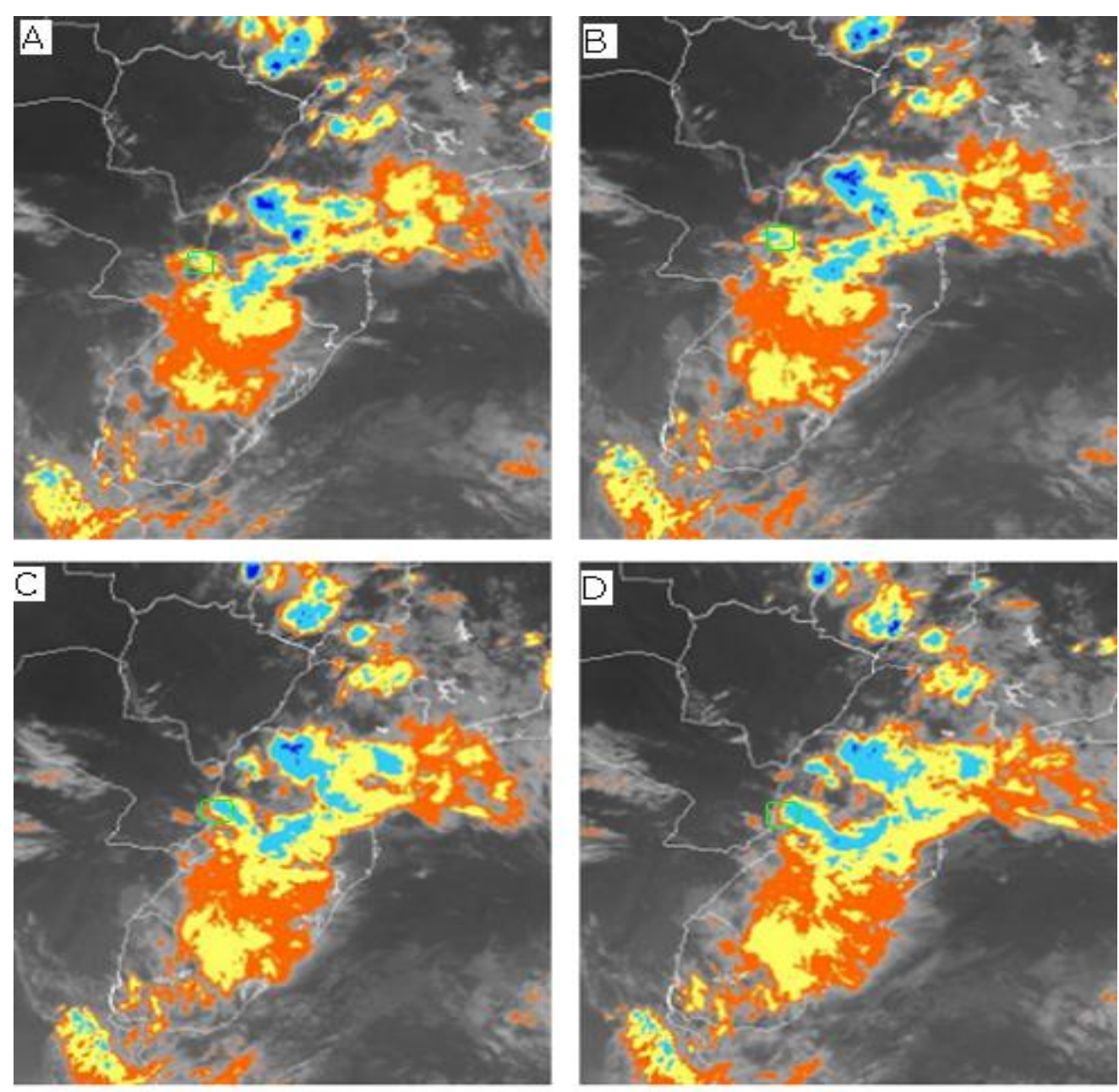

$-80$

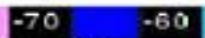

$-50$

$-40$

$-30$

Figura 9 - Imagens de satélite GOES-13 do canal infravermelho de temperatura realçada (A) 07/09 22:00UTC, (B) 07/09 22:30UTC, (C) 07/09 23:00UTC, (D) 07/09 23:30UTC, 0 polígono em verde indica a região afetada pelas tempestades.

A Figura 12 indica, no nível de $850 \mathrm{hPa}$, o transporte de umidade de norte em baixos níveis na região de estudo e em toda a área de influência da BNOA, intensificando-se no dia 07/09 como se observa na Figura 12C. Concordando com o mencionado por Seluchi e Saulo (2012), que a BNOA assim como a $\mathrm{BCH}$ se desenvolve em uma atmosfera mais instável do ponto de vista termodinâmico, com maior conteúdo de umidade sendo afetada por precipitações mais abundantes, dentro de uma massa de ar mais típica das latitudes tropicais. É possível analisar a relação existente entre as máximas velocidades do vento norte (Figura 2 ), e as variações positivas de umidade em $850 \mathrm{hPa}$ (Figura 12), sendo provável a associação com o transporte da Região Amazônica que também contribui com os valores de temperatura (Figura 11). 


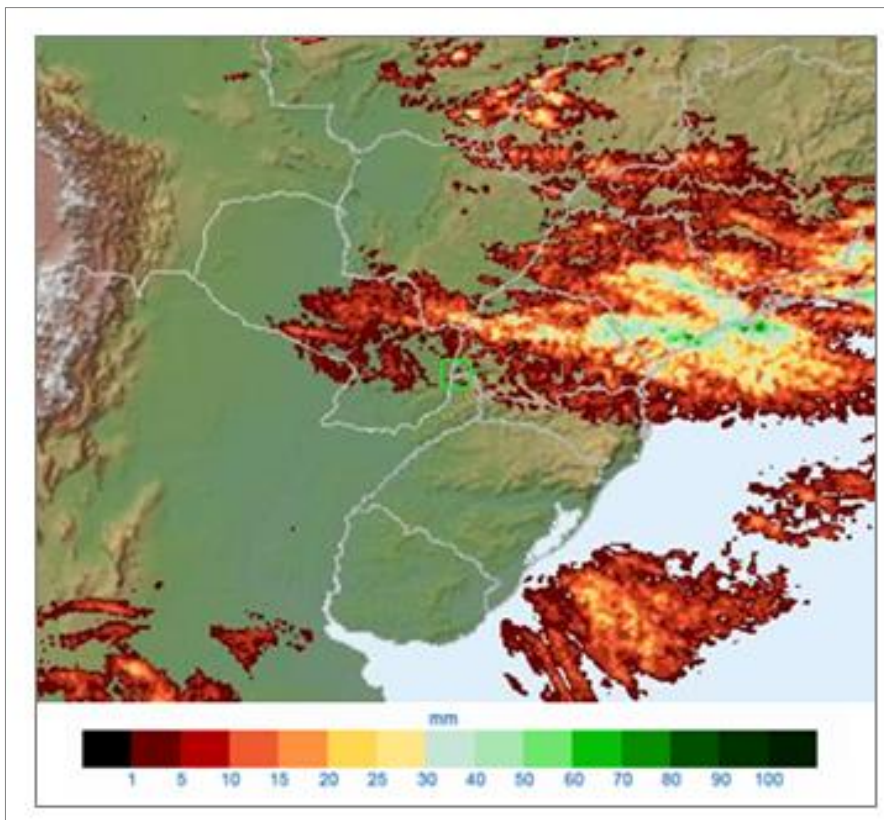

Figura 10 - Precipitação acumulada diária pelo Hidroestimador 08/09 12UTC, o polígono em verde indica a região afetada pelas tempestades.

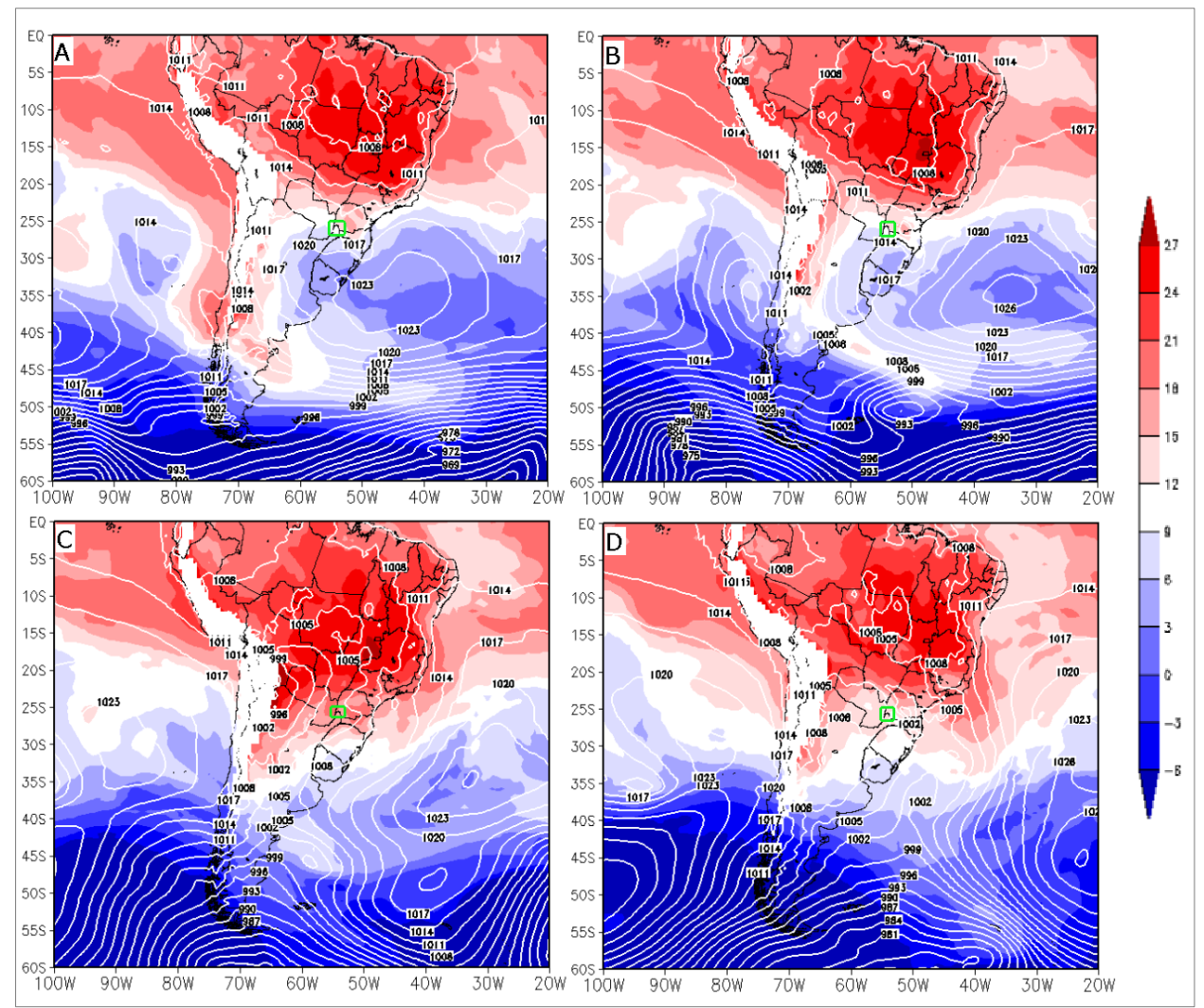

Figura 11 - Campo de pnmm em hPa (contorno em branco) e temperatura do ar (sombreado) em ${ }^{\circ} \mathrm{C}$ em $850 \mathrm{hPa}$. (A) 05/09 18UTC, (B) 06/09 18UTC, (C) 07/09 18UTC, (D) $08 / 09$ 18UTC. 


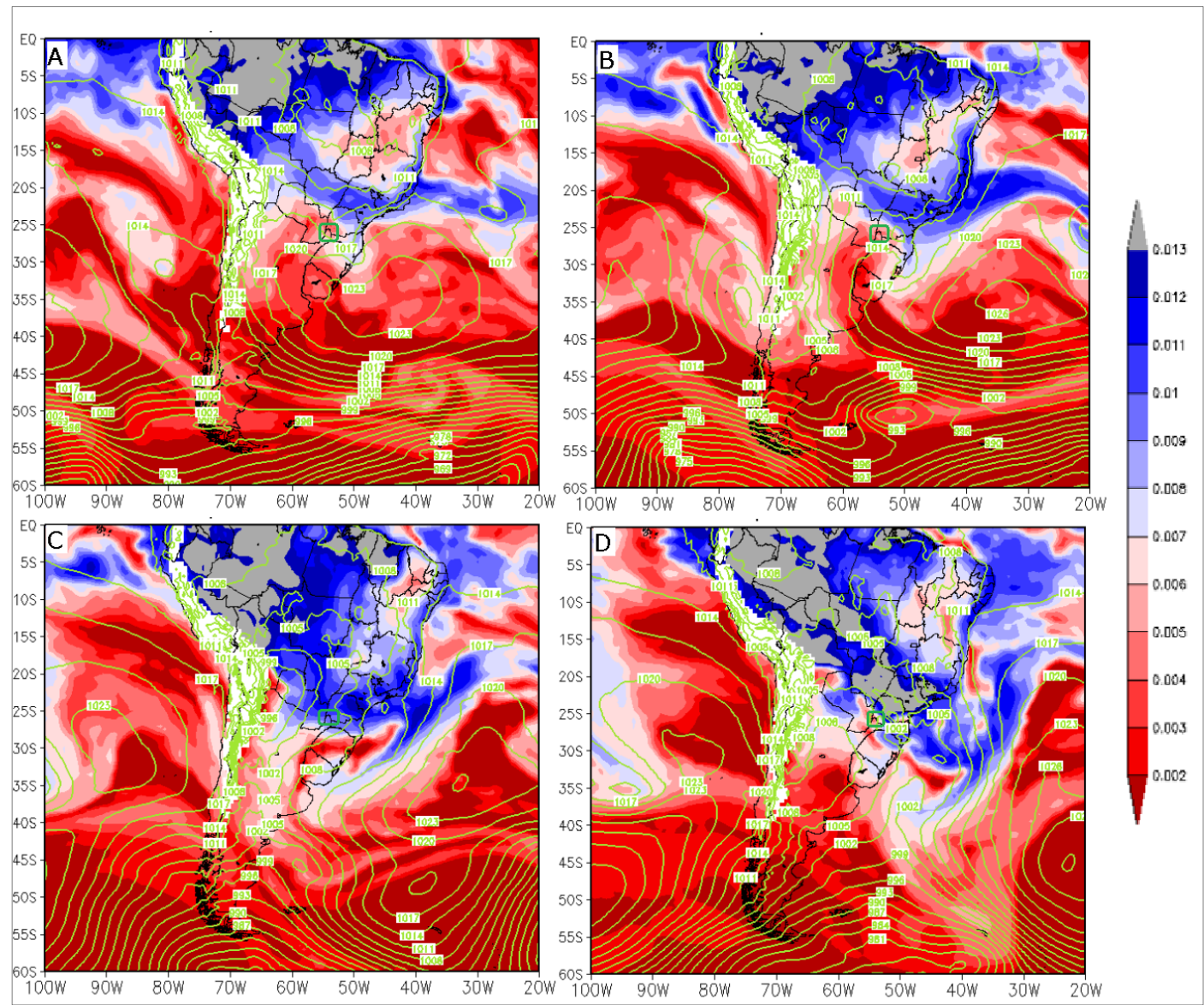

Figura 12 - Campo de pnmm em hPa (contorno em verde) e umidade específica (sombreado) em g kg-1 em $850 \mathrm{hPa}$. (A) 05/09 18UTC, (B) 06/09 18UTC, (C) 07/09 18UTC, (D) 08/09 18UTC, o polígono em verde indica a região afetada pelas tempestades.

\section{CONCLUSÕES}

Em suma ao analisado pode-se inferir que o evento referente as tempestades ocorridas em setembro de 2015 no oeste do estado do Paraná, principalmente na cidade de Foz do Iguaçu, foram provocadas por forçantes térmicas, oriundas de baixos níveis, e forçantes dinâmicas, proveniente de altos níveis, concordando com a literatura especializada. Esta influência se manifestou sob extremos pluviométricos acima da média (verificado pelas normais climatológicas do mês de setembro), granizo e fortes ventos, ocasionando problemas com consequências sociais, ambientais e econômicas para a população.

A compreensão das forçantes que desencadeiam os eventos de chuva intensa é de extrema necessidade, tendo em vista os transtornos e os prejuízos ocasionados. Aqui, notou-se a influência de forçantes de altos níveis, como a presença da corrente de jato, escoamento difluente e advecção de vorticidade ciclônica, bem como forçantes de baixos níveis, como advecção de temperatura e transporte de umidade devido ao escoamento de norte, favorecido pela presença do jato de baixos níveis. Tal escoamento de norte favoreceu a 
intensificação de um dos sistemas típicos referentes às tempestades convectivas na região de estudo, a Baixa do Noroeste Argentino. Entretanto, há necessidade de estudos que abarquem outras forçantes meteorológicas, bem como as influências remotas ou mesmo antrópicas, para possibilitar medidas de planejamento ambiental para o município de Foz do Iguaçu.

\section{REFERÊNCIAS BIBLIOGRÁFICAS}

ANA-Agencia Nacional de Águas. HIDROWEB-Sistema de Informações Hidrológicas. Series Históricas de Estações. Disponível em <http://www.snirh.gov.br/hidroweb/publico/medicoes_historicas_abas.jfs>. Acesso em 25 de abril de 2018.

AMARAL, Lia Martins Costa do. Análise de complexos convectivos ocorridos na região sul da América do Sul durante o período de 2005 a 2010. São José dos Campos. INPE, 2014.

BLUESTEIN, H.B. Synoptic-Dynamic Meteorology in Midlatitudes. Volume II: Observations and theory of weather systems. Oxford University Press. Oxford, 1993. 594p.

BONNER, W. D. Climatology of the low level jet. Monthly Weather Review, v. 96, n. 12 , p. 833-850, 1968.

CEMADEN-Centro Nacional de Monitoramento e Alertas a Desastres Naturais. Download-Dados Pluviométricos. Disponível em <http://www.cemaden.gov.br/mapainterativo/\#>. Acesso em 25 de abril de 2018.

COUTINHO, M.D.L.; COSTA, M.S.; GOMES, A.C.S.; MORAIS, M.D.C.; JACINTO, L.V.; LIMA, K.C.; SAKAMOTO, M.S. Estudo de caso: Evento extremo no Estado do Ceará entre os dias 03 e 04 de janeiro de 2015. Revista Brasileira de Climatologia. v. 20, p. 182-198, 2017.

ESCOBAR, G.C.J.; SELUCHI, M.E. Classificação sinótica dos campos de pressão atmosférica na América do Sul e sua relação com as baixas do Chaco e do noroeste argentino. Revista Brasileira de Meteorologia. v.27, n. 3, p. 365-375, 2012.

FONSECA, P.; VEIGA, J. A.; CORREIA, F. W.; CHAN, C.; LYRA, A. An analysis of rainfall extremes in the Northern South America and their behaviors for future climate based on A1B scenario. Revista Brasileira de Climatologia. v. 20, p. 117134, 2017.

GAN, M.; RODRIGUES, I. R.; RAO, V. B. Monção na América do Sul. In: Tempo e Clima no Brasil. 2« ed. São Paulo: Oficina de Textos, 2009, Cap. 3, p. 297-316.

GAZETA DO POVO. Choveu o equivalente a $20 \%$ para todo o mês em Foz do Iguaçu. Vida e Cidadania. Curitiba. 09 de set. de 2015. Disponível em < http://www.gazetadopovo.com.br/vida-e-cidadania/choveu-o-equivalente-a-20para-todo-o-mes-em-foz-do-iguacu-e8neim8j4r7f579z76zhrgtee>. Acesso em 20 de fevereiro de 2018.

GELARO, R.; MCCARTY, W.; SUÁREZ, M.J.; TODLING, R.; MOLOD, A.; TAKACS, L.; RANDLES, C.A.; DARMENOV, A.; BOSILOVICH, M.G.; REICHLE, R.; WARGAN, K.; COY, L.; CULLATHER, R.; DRAPER, C.; AKELLA, S.; BUCHARD, V.; CONATY, 
A.; SILVA, A.M.; GU, W.; KIM, G-K.; KOSTER, R.; LUCCHESI, R.; MERKOVA, D. ; NIELSEN, J.E.; PARTYKA, G.; PAWSON, S.; PUTMAN, W.; RIENECKER, M.; SCHUBERT, S.D.; SIENKIEWICZ, M.; ZHAO, B. The Modern-Era Retrospective Analysis for Research and Applications, Version 2 (MERRA-2). Journal of Climate, v. 30, p. 5419-5454, 2017.

INMET-Instituto Nacional de Meteorologia. Estações Automáticas. Disponível em <http://www.inmet.gov.br/portal/index.php?r=estacoes/estacoesAutomaticas>. Acesso em 25 de abril de 2018.

GRIMM, M. A. Clima da Região Sul do Brasil. In: Tempo e Clima no Brasil. 2 ed. São Paulo: Oficina de Textos, 2009, Cap. 2, p. 259-275.

G1. Chuva de granizo atinge cidades do oeste do Paraná e causa estragos. G1 Paraná, Paraná. 07 de set. de 2015. Disponível em < http://g1.globo.com/pr/oeste-sudoeste/noticia/2015/09/chuva-de-granizo-

atinge-cidades-do-oeste-do-parana-e-causa-estragos.html/>. Acesso em 24 de fevereiro de 2018.

HOLTON, J. R. Synoptic-scale motions I: Quasi-Geostrophic analysis. In: An Introduction to Dynamic Meteorology. 4 ed. Academic Press, 2004, Cap. 6, p. 139-181.

IAPAR-Instituto Agronômico do Paraná. Cartas Climáticas do Paraná. Disponível em <http://www.iapar.br/>. Acesso em 15 de fevereiro de 2018.

JONES, C.; HOREL, J.D. A circulação da Alta da Bolívia e a atividade convectiva sobre a América do Sul. Revista Brasileira de Meteorologia, v. 5, n. 1, p. 379387, 1990.

KÖPPEN, W. Climatologia. México: Fundo de Cultura Econômica, 1931. 478 p.

LENTERS, J.D.; COOK, K.H. 1999. Summertime precipitation variability over South America. Role of the large-scale Circulation. Monthly Weather Review. American Meteorological Society, v. 127, p. 409-431, 1999.

LICHTENSTEIN, E. R. La Depresión del Noroeste Argentino. Tese de doutorado, Universidade de Buenos Aires. 223f. 1980.

LIMA, A. P.; AMORIM, M. C. C. T. Análise de episódios de alagamentos e inundações urbanas na cidade de São Carlos a partir de notícias de jornal. Revista Brasileira de Climatologia, v. 15, p. 182-204, 2014.

LOHMANN, M.; SANTOS, L.J.C. Determinação de padrões de chuva crítica para ocorrências de alagamentos em Curitiba-PR utilizando rede neural artificial SOM (Self Organizing Map). Revista Brasileira de Climatologia, v. 17, p. 227-245, 2015.

MADDOX, R.A.; DOSWELL III, C.A. An Examination of Jet Stream Configurations, $500 \mathrm{mb}$ Vorticity Advection and Low-Level Thermal Advection Patterns During Extended Periods of Intense Convection. Monthly Weather Review, v. 110, p. 184-197, 1982.

MARENGO, J. A. Mudanças climáticas e eventos extremos no Brasil. Fundação Brasileira para o Desenvolvimento Sustentável - FBDS. 2010. Disponível em <http://www.fbds.org.br/fbds/IMG/pdf/doc-504.pdf>. Acesso em $19 \mathrm{fev}$. de 2018. 
NUNES, A. B., PEREIRA, R. S. Estimativa de eventos de precipitação com potencial para alagamentos urbanos no Rio Grande do Sul. In: Nunes, A.B. E Mariano, G.L. (Org), Meteorologia em Tópicos - Volume 4. Pelotas: Clube de Autores, p. 273-313, 2017.

NUNES, A. B. Case Study of Upper Tropospheric Meteorological Systems on South America: Synoptic Analysis, Anuário do Instituto de Geociências, v. 40, p. 70-82, 2017. DOI: dx.doi.org/10.11137/2017_1_70_82

NUNES, A. B.; DA SILVA, G.C. Climatology of extreme rainfall events in eastern and northern Santa Catarina State, Brazil: Present and future climate, Revista Brasileira de Geofísica, v.31, n.3, p.413-425, 2013. DOI: dx.doi.org/10.22564/rbgf.v31i3.314

REBOITA, M. S.; GAN, M. A.; ROCHA, R. P.; AMBRIZZI, T. Regimes de precipitação na América do Sul: Uma revisão bibliográfica. Revista Brasileira de Meteorologia, v. 25, n. 2, p. 185-204, 2010.

REBOITA, M. S.; MARIETTO, D. M.; SOUZA, A.; BARBOSA, M. Caracterização atmosférica quando da ocorrência de eventos extremos de chuva na região sul de Minas Gerais. Revista Brasileira de Climatologia, v. 21, p. 20-37, 2017.

SANCHES, F. O.; BALEN, D. S.; SILVA, R. V.; ROSA, K. K.; RADÜNZ, A. Chuvas no Rio Grande do Sul: Um estudo sobre as precipitações acumuladas intensas no Alto Uruguai Gaúcho. Revista Brasileira de Climatologia, v. 15, p. 143-162, 2015.

SALIO, P.; NICOLINI, M.; ZIPSER, E. J. Mesoscale convective systems over South America and their relationship with the South American low-level jet. Monthly Weather Review, v. 135, p. 1290-1309, 2007.

SELUCHI, M. E.; SAULO, A. C. Baixa do noroeste argentino e Baixa do Chaco: Características, diferenças e semelhanças. Revista Brasileira de Meteorologia. v. 27, n. 1, p. 49-60, 2012.

SELUCHI, M. E.; GARREAUD, R. D. Campos médios e processos físicos associados ao ciclo de vida da Baixa do Chaco. Revista Brasileira de Meteorologia, v. 27, n. 4, p. 447-462, 2012.

SELUCHI, M. E.; BEU, C. M.; ANDRADE, K. M. Características das frentes frias com potencial para provocar chuvas intensas na região serrana de Rio de Janeiro. Revista Brasileira de Climatologia, v. 18, p. 361-376, 2016.

STEINKE, E.T.; RESENDE, M.S.; CAVALCANTI, L. Sistemas atmosféricos geradores de eventos extremos de precipitação em outubro de 2006 no distrito federal: uma análise geográfica dos desastres. Revista Brasileira de Climatologia, v. 2, p. 23-34, 2006.

UH-Última Hora. Granizada afectó a unas 30.000 personas en Presidente Franco. Asunción. 08 de set. de 2015. Disponível em < http://www.ultimahora.com/granizada-afecto-unas-30.000-personaspresidentefranco-n928725.html>. Acesso em 24 de fevereiro de 2018.

WANDERLEY, L. S.; NÓBREGA, R. S.; MOREIRA, A. B.; ANJOS, R. S.; ALMEIDA, C. P. As chuvas na cidade do Recife: uma climatologia de extremos. Revista Brasileira de Climatologia, v. 22, p. 149-164, 2018. 